\title{
MILP approaches to sustainable production and distribution of meal elements
}

\author{
Akkerman, Renzo; Wang, Yang; Grunow, Martin
}

Published in:

International Conference on Computers \& Industrial Engineering, 2009.

Link to article, DOI:

10.1109/ICCIE.2009.5223667

Publication date:

2009

Document Version

Publisher's PDF, also known as Version of record

Link back to DTU Orbit

Citation (APA):

Akkerman, R., Wang, Y., \& Grunow, M. (2009). MILP approaches to sustainable production and distribution of meal elements. In International Conference on Computers \& Industrial Engineering, 2009.: CIE 2009. IEEE. https://doi.org/10.1109/ICCIE.2009.5223667

\section{General rights}

Copyright and moral rights for the publications made accessible in the public portal are retained by the authors and/or other copyright owners and it is a condition of accessing publications that users recognise and abide by the legal requirements associated with these rights.

- Users may download and print one copy of any publication from the public portal for the purpose of private study or research

- You may not further distribute the material or use it for any profit-making activity or commercial gain

- You may freely distribute the URL identifying the publication in the public portal

If you believe that this document breaches copyright please contact us providing details, and we will remove access to the work immediately and investigate your claim. 


\title{
MILP approaches to sustainable production and distribution of meal elements
}

\author{
Renzo Akkerman, Yang Wang, Martin Grunow \\ Department of Management Engineering, Technical University of Denmark, \\ Produktionstorvet 424, 2800 Kgs. Lyngby (Copenhagen), Denmark \\ (renzo@man.dtu.dk / ywan@man.dtu.dk / grunow@man.dtu.dk)
}

\begin{abstract}
This paper studies the production and distribution system for professionally prepared meals, in which a new innovative concept is applied. The concept aims to improve the sustainability of the system by distributing meal elements super-chilled in the conventional cold chain. Here, sustainability comprises economic, environmental and social aspects. The impacts on and trade-offs between the different dimensions of sustainability are discussed, and combined with aspect of product quality. Furthermore, we identify the important planning decisions in relation to production and distribution and organise these in a decision hierarchy. Based on these discussions, decision support models based on mixed-integer linear programming are developed for the planning tasks on the tactical level, including decision-making on packaging options and delivery structures. The resulting models can be used to support production and distribution planning, and also evaluate the performance of and quantify the trade-offs between the different sustainability dimensions.
\end{abstract}

Keywords: Food industry, catering, distribution management, planning, MILP, decision support

\section{INTRODUCTION}

The management of food supply chains is receiving more and more attention. Especially, with the growing importance of the catering sector, which increasingly uses professionally (i.e. industrially) prepared meal elements. The distribution management of such prepared food is becoming a new challenge for supply chain managers. This also has background in the fact that the culinary quality of foodservice meals is a much debated issue throughout Europe [1-3] and the consumption of prepared meals is growing and will continue to grow in the foreseeable future, due to trends in demography and life-style (more elderly people, more one-person households in the future, and more out-of-home dining) [4].

This paper studies the supply chain for professionally prepared meals, in which a new innovative concept for producing and distributing the main components is applied. The objective of this concept is to achieve a higher quality of the meals in a sustainable way. The new concept aims to improve the sustainability of the production and distribution system, and to prolong the shelf lives of the meals by distributing them super-chilled in the conventional cold chain at $+2^{\circ} \mathrm{C}$ or $+5^{\circ} \mathrm{C}$. This paper adopts a definition of the catering food supply chain that consists of the following stages: a production site, a distribution centre and several professional kitchens.
The remainder of this paper is organized as follows. The next section discusses professionally prepared meals in more detail, also introducing some of the technological aspects that will be used in the rest of the paper. Subsequently, the challenges in relation to sustainability are discussed, followed by the identification of relevant planning decisions, and the trade-offs related to them. Then, we develop a mathematical model to support decision making on tactical distribution network planning, followed by our conclusions.

\section{PROFESSIONALLY PREPARED MEALS}

Meal elements are semi-prepared convenience components based typically on meat, fish or vegetables, which are produced in industrial settings. They can be used in situations where tedious, labour-demanding, or unhealthy operations in professional kitchens can be reduced [5]. Meal elements may be super chilled, which involves a partial freezing of the products and which slows down quality deterioration during distribution [6].

Instead of processing food products in a freezing tunnel to $-35^{\circ} \mathrm{C}$, they are processed for a shorter time to $-6^{\circ} \mathrm{C}$ or $-8^{\circ} \mathrm{C}$ and afterwards distributed in the conventional cold chain at $+2^{\circ} \mathrm{C}$ or $+5^{\circ} \mathrm{C}$. The temperature of the food product will then increase during transportation. Due to the fact that super chilling creates a thermal buffer, it takes some time for the temperature of the food product to increase. Especially around $-1^{\circ} \mathrm{C} /-2^{\circ} \mathrm{C}$ the thawing process is quite slow.

978-1-4244-4136-5/09/\$25.00@2009IEEE 


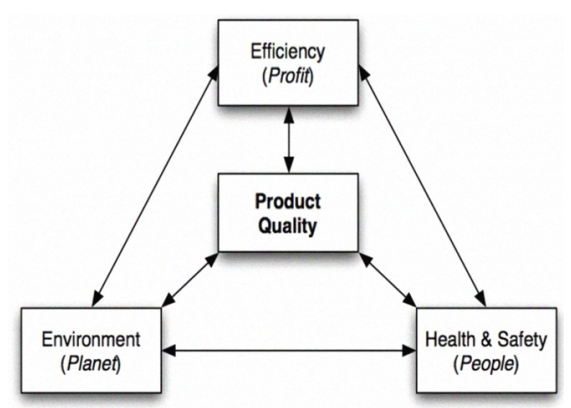

Figure 1. Illustration of the trade-offs present between food product quality and the different

In order to determine the temperature status of the food product and insure the quality of the product when it is used in professional kitchens, the whole thawing process during distribution needs to be tracked in detail. The temperature of the food product is not easy to track but its enthalpy (from which temperature and quality can be deduced) is. Enthalpy is an important property of food products, reflecting the energy stored in the product. Enthalpy changes are mainly based on the heat transfer between a food product and its surrounding environment, based on characteristics of the product and the environment in which it is located. For a more detailed discussion of enthalpy, we refer to [7].

\section{SUSTAINABILITY}

Over the last years, sustainability has become of increasing importance in the food industry [8]. So, although product quality is a main concern in the production and distribution of food products, at the same time due consideration must be given to the various aspects of sustainability [9]. To assess sustainability in this paper, the analysis thus not only focuses on commonly used cost-based performance indicators, but also on environmental and social aspects. Figure 1 illustrates this so-called triple bottom line [10] and its relation to product quality. In the following, we briefly discuss each of the dimensions of sustainability in light of the proposed production and distribution system for meal elements.

First, in relation to efficiency, the focus is mainly on the costs of production and distribution. Here, production costs are dependent on the starting enthalpy of the product (determined by the time the product spends in the freezing tunnel) and the choice of packaging materials. Distribution costs are largely determined by the number of times we are delivering product to our customers. Secondly, environmental aspects largely result from energy usage and waste. Energy usage relates to the production system, where it depends on the freezing time for each product, and the distribution, where additional shipments obviously increase the environmental impact through $\mathrm{CO}_{2}$ emissions. In comparison with the normal distribution of frozen products, the distribution concept described in this paper uses the conventional cold chain, which significantly reduces the energy consumption. Finally, social aspects are traditionally linked to a firm's corporate responsibility and to the health and safety of its employees. For this project, this mainly relates to the work environment at customer locations. People working in institutional kitchens get to use partially frozen meal elements, which are more stiff and easier to handle. For the society as a whole, the project aims to provide high-quality food in institutional kitchens, and would thereby benefit important population segments such as the elderly and school children.

Even more important than the performance on individual sustainability dimensions are the interactions between the different dimensions and the quality of the food product (also illustrated in Figure 1).

The quality of products, at the core of the interactions, is highly linked to each of the three dimensions. For instance, quality could be increased by an increasing delivery frequency of the product to the customer, but this would reduce the economic and environmental performance by an increase in the number of shipments that have to be performed. If we would on the other hand choose to increase shipment volumes and decrease the number of shipments, we would reduce the environmental impact related to cooling the product during transportation. Also, we would likely increase the efficiency of the transportation network. However, the product quality would be negatively affected by this decision, as part of the shipment would have to be stored at the customer site to cover future demand, leading to quality degradation of the food product, and possibly cause product waste.

Another example is the choice of packaging materials. This not only affects the amount and type of waste, but also the handling effort of the people involved, and the quality deterioration of the meal elements. Choosing polystyrene boxes would for instance slow down the thawing process after super chilling, thereby reducing quality degradation. On the other hand, the material is more expensive and less environmentally friendly than regular cardboard.

As might be clear from the examples, especially interactions between economic and environmental performance are plentiful. Whether these interactions lead to synergies or trade-offs is something that is still discussed in the literature, and depends on industry-specific characteristics [11]. To tackle this, an interdisciplinary approach, combining operations management insights with technological expertise is necessary, which has been discussed in both the managerial literature $[12,13]$ and the engineering literature $[14,15]$. The specific setting discussed in this paper is an example of such an interdisciplinary research project, and could therefore provide additional 
insight in the interactions between economic and environmental performance in a specific situation.

In conclusion, the decisions that have to be made in the design and operation of the production and distribution network lead to complex interactions between various performance indicators, where it is hard to evaluate the various trade-offs that might occur.

\section{PLANNING DECISIONS}

To analyze the trade-offs described in the previous section, we first identify the important decisions and organise these in a decision hierarchy, a well-established method to approach complex decision problems $[16,17]$.

The total task of planning the production and distribution system can be decomposed in three hierarchical levels, reflecting strategic, tactical and operational decisions. The strategic decisions cover the design of the distribution network, which is regarded as given in this paper. The tactical, mid-term planning level mainly deals with decisions on how much to produce in the foreseeable future, and what delivery structure to use in relation to customers. This includes how often we have deliveries to specific customers, affecting to a large extent the total transportation distance covered (relating to cost performance as well as environmental performance). On the tactical level, we also find interesting trade-offs with different packaging options and starting enthalpy levels, as these factors influence the eventual enthalpy level at the customer, and hereby determine how much future demand can already be covered by a shipment. Obviously, these decisions are all very much interrelated, and are therefore combined in one planning model to provide decision support. These decisions then set the targets for the operational, short-term level, in which more detailed decisions on vehicle loading and vehicle routing are made. In response, the short-term planning level might also provide feedback to the mid-term level.

In the remainder of this paper, we limit ourselves to the tactical network planning problem, as the decisions made on that decision level have a large impact on the eventual performance of the distribution system. Furthermore, we focus on the economic and environmental dimension of sustainability. This means we model the network and its characteristics in relation to costs and environmental impact, building on previous work on production and distribution planning. The discussion on sustainability factors in this paper will be the main background for this, and the resulting model will allow us to provide decision support in relation to the trade-off between economic and environmental performance of the production and distribution system.

\section{TACTICAL NETWORK PLANNING MODEL}

\subsection{Problem description}

In this paper, we consider a single production site producing one kind of fresh food product, with the possibility to produce this product at different temperatures, i.e. enthalpy levels, and in different packaging types. This product is then supplied to a distribution centre that cross-docks the product and transports it further down to several customers. The whole amounts of product produced on one day for one customer should be packed in one type of packages and have the same starting enthalpy level. The production costs are determined by the enthalpy level of the products and proportional to the quantity produced. Lower enthalpy levels require higher production cost. The packaging costs are determined by the type of package used and the quantity packed. Since the freezing tunnel operation is the bottleneck of the production process, manufacturing capacity of the production site is mainly limited to the daily time available on the freezing tunnel at the production site.

Customers are mainly professional kitchens whose demands are deterministic and have to be met before the due date. Products can be delivered at customers' sites before their due date and then be stored there until it is used. There are however limited storage capacities at the customers' sites. In order to be sure about the food quality, when the product is used at customers' site, it must be below a given enthalpy level (specified by the customer). All the transportation is performed in the conventional cold chain, and transportation costs are proportional to the number of shipments and their length The products' enthalpy increase is according to its package type and the transportation or storage time. The objective is to minimize the sum of production costs, transportation costs, and packaging costs.

\subsection{Tracking enthalpy changes}

Based on experiments done in a parallel research project, relations between enthalpy and time were identified for fish and certain vegetables. Most food products have similar enthalpy curves, as these relationships mainly depend on the water content of a product. In order to keep track of enthalpy increases, the trend of the enthalpy increases can be estimated fairly well with a logarithmic function (see [18] for more details). Using the estimated trend, we can calculate the expected enthalpy of food products after storage for given time intervals, temperatures and package types. For a given set of these parameters, the reaction is logarithmic, but can be transformed to a linear relationship by taking its exponent. This means that the enthalpy change during a specified time period can be determined for each possible package type, and the outcome can be used as parameters in the MILP model for tactical planning developed later in this paper. For this to be possible, a discrete scale is developed for the enthalpy level, and used as an index in the MILP model (see also [19]). 


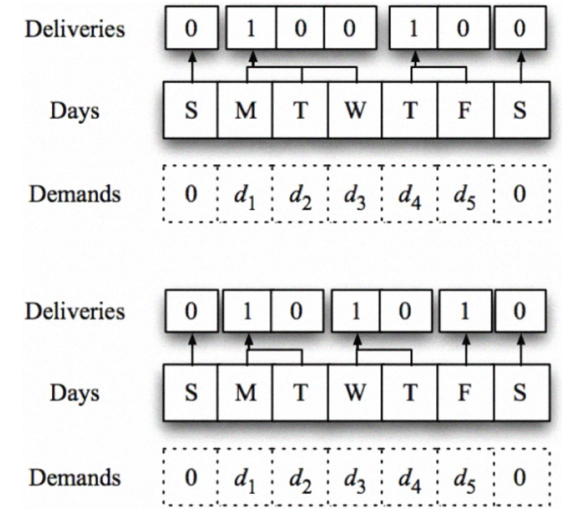

Figure 2. Two examples of assigning delivery structures to a week's demand.

\subsection{Choosing delivery structures}

In the distribution system, customers do not need to be served every day. Customers' demands of several days can be satisfied in one shipment (providing temperature changes and quality changes allow for this). To model this, we introduce the concept of delivery structures. Delivery structures are related to days of demands covered by a shipment. As illustrated in Figure 2, delivery structure ' 1 ' means we satisfy demand for one day with a delivery on that day, ' 10 ', means we satisfy demand of 2 days by a shipment on the first day, etc. We also introduce delivery structure ' 0 ', to denote that there is no demand and no shipment on a specific day. To decide on which day to serve a customer is to combine these delivery structures for a customer.

In Figure 2, two examples are shown for a situation with a week of demand for a customer. In both cases, there is no demand in the weekend, leading to the single-zero delivery structures for those days. In the first example, demands during the week are covered with two shipments, one on Monday and one on Thursday. In the second example, three shipments are used to cover the demand: on Monday, Wednesday, and Friday. How these delivery structures are assigned is a complex decision problem, depending on customer requirements and quality degradation of the product (during transport and storage), involving cost trade-offs between packaging material, enthalpy level and transportation.

\subsection{Problem formulation}

In this section, the tactical planning model is formulated, based on the delivery structure concept outlined in the previous subsection. Below we will first define sets, parameters and decision variables. Then a model that aims to optimize the economic dimension will be presented and discussed. Subsequently, an alternative version of this model, aiming to optimize the environmental dimension will be presented, and the integration of the two models will be discussed. $f \in F \quad$ set of indices of delivery structures: $\{0,1,10$, $100,1000,10000\}$, where $F=\{1, \ldots, 6\}$ in this case. The set $F$ is divided into two subsets: $F_{I}=\{1\}$ is the index of delivery structure $\{0\}$, $F_{2}=\{2,3,4,5,6\}$ are indices for $\{1,10,100$, $1000,10000\}$. We observe that delivery structures $f \in F_{2}$ have exactly $f-1$ days.

$j \in J \quad$ set of customers

$h \in H \quad$ set of all enthalpy levels, $H=\left\{h_{\min }, \ldots, h_{\max }\right\}$

$t \in T \quad$ set of days, $T=\left\{1, \ldots, T_{0}\right\}$

$p \in P \quad$ set of available package types.

\section{Parameters:}

$w_{h} \quad$ cost for producing one unit of product with enthalpy level $h$

$v_{p} \quad$ cost for packaging one unit of product using package type $p$

$k^{(1)} \quad$ cost for transporting one shipment of product from production site to distribution centre

$k_{j}^{(2)} \quad$ cost for transporting one shipment of product from distribution centre to customer $j$

$l_{h} \quad$ freezing time required to produce one unit of product with enthalpy level $h$

$a_{t} \quad$ production time available in freezing tunnel on day $t$

$g_{j t} \quad$ storage capacity at customer $j$ on day $t$

$\Delta h_{p} \quad$ enthalpy increase per day at customer sites for package choice $p$

$d_{j t} \quad$ demand of customer $j$ on day $t$

$h_{\min } \quad$ minimum enthalpy level possible to produce

$h_{\max } \quad$ maximum enthalpy level allowed by customers

$M \quad$ a relatively large number

Decision variables:

$x_{p j t} \quad$ binary variables indicating whether delivery structure $f$ is used for customer $j$ with package type $p$, and $t$ the start day of this structure

$y_{j t} \quad$ binary variables indicating a shipment from the distribution centre to customer $j$ on day $t$

$z_{t} \quad$ binary variables indicating whether there is a shipment between the production site and the distribution centre on day $t$

Objective function:

$$
\begin{aligned}
& \operatorname{Min} Z_{1}= \\
& \begin{aligned}
\sum_{t \in T} \sum_{p \in P} \sum_{j \in J} \sum_{f \in F_{2}}\left(w_{h_{\max }}-(f-2) \cdot \Delta h_{p}\right. \\
\end{aligned} \\
& \left.\quad+\sum_{t \in T}\right) \cdot \sum_{i=0}^{f-2} d_{j, t+i} \cdot x_{p j t} \cdot z_{t}+\sum_{t \in T} \sum_{j \in J} k_{j}^{(2)} y_{j t}
\end{aligned}
$$

subject to

$$
\sum_{j \in J} \sum_{p \in P} \sum_{f \in F_{2}} l_{h_{\max }-(f-2) \cdot \Delta h_{p}} \cdot \sum_{i=0}^{f-2} d_{j, t+i} \cdot x_{p j f t} \leq a_{t} \forall t \in T
$$

Sets: 


$$
\begin{aligned}
& \left(h_{\text {max }}-(f-2) \cdot \Delta h_{p}\right) \cdot x_{p j f t} \geq b_{\text {min }} \\
& \forall p \in P, \forall j \in J, \forall f \in F_{2}, \forall t \in T \\
& \sum_{t \in T} \sum_{p \in P} x_{p j 1 t}+\sum_{t \in T} \sum_{p \in P} \sum_{f \in F_{2}}(f-1) \cdot x_{p j f t}=T_{0} \quad \forall j \in J \\
& d_{j t} \cdot \sum_{p \in P} x_{p j 1 t}=0 \quad \forall t \in T, \forall j \in J \\
& \sum_{i=1}^{f_{0}-2} \sum_{p \in P} \sum_{f \in F} x_{p, j, f, t+i} \leq M\left(1-\sum_{p \in P} x_{p, j, f_{0}, t}\right) \\
& \forall f_{0} \in F_{2} \backslash\{2\}, \forall t \in T, \forall j \in J \\
& \sum_{p \in P} \sum_{f \in F} x_{p j f t} \leq 1 \quad \forall j \in J, \forall t \in T \\
& \sum_{p=P} \sum_{f \in F_{2}} x_{p j t t} \leq M \cdot y_{j t} \quad \forall j \in J, \forall t \in T \\
& \sum_{j \in J} y_{j t} \leq M \cdot z_{t} \quad \forall t \in T \\
& \sum_{i=m+1}^{f-2} d_{j, t+i} \cdot x_{p j f t} \leq g_{j, t+m} \quad \forall j \in J, \forall t \in T, \\
& \forall f \in F, \forall p \in P, \forall m=0, \ldots, f-3 \\
& x_{p j t t} \in\{0,1\} \quad \forall j \in J \quad \forall t \in T \quad \forall f \in F \forall p \in P \\
& y_{j t} \in\{0,1\} \quad \forall j \in J, \forall t \in T \\
& z_{t} \in\{0,1\}, \forall t \in T
\end{aligned}
$$

In the above formulation, the objective function (1) aims to minimize the total cost, consisting of production costs, packaging costs and transportation costs. Constraints (2) and (3) enforce the production capacity constraints and make sure that there is no production below the minimum possible enthalpy level. Constraints (4) to (7) mean that all the customers' demand should be satisfied, there are no overlapping delivery structures and exactly one package type is selected for the product produced on one day for one customer. Constraints (8) and (9) enforce that there should be shipments from production site to distribution centre and from distribution centre to customers if we need to satisfy the customer's demand on that day. Constraints (10) enforce the customers' storage capacity constraints. Finally, constraints (11) to (13) are binary variables constraints.

The above model only focuses on cost aspects, covering the economic dimension of sustainability. To formulate a similar model, but focusing on environmental impact, we introduce the following additional parameters:

$e_{h}^{(1)}$ environmental impact of producing one product
$e^{(2)} \quad \begin{aligned} & \text { unit with enthalpy level } h \\ & \text { environmental impact for transporting one }\end{aligned}$ shipment of product from production site to distribution centre

$e_{j}^{(3)} \quad$ environmental impact for transporting one shipment of product from distribution centre to customer $j$

$e_{p}^{(4)}$ environmental impact for packaging one product unit using package type $p$

To make sure it is possible to determine the total environmental impact, all these parameters will have to be expressed in a common unit, such as $\mathrm{kg} \mathrm{CO}_{2}$ equivalents [20]. These parameters can then be used to reformulate the presented model, focusing on the minimization of environmental impact instead of costs:

$$
\begin{aligned}
& \operatorname{Min} Z_{2}= \\
& \sum_{t \in T} \sum_{p \in P} \sum_{j \in J} \sum_{f \in F_{2}}\left(e_{b-(f-2) \cdot \Delta h_{p}}^{(1)}+e_{p}^{(4)}\right) \cdot \sum_{i=0}^{f-2} d_{j, t+i} \cdot x_{p j t t} \\
& \quad+\sum_{t \in T} e^{(2)} \cdot z_{t}+\sum_{t \in T} \sum_{j \in J} e_{j}^{(3)} \cdot y_{j t}
\end{aligned}
$$

subject to constraints (2) - (13)

As can be seen, the only change is in the objective function, as the constraints from the initial model cover technical constraints relating to production and distribution, which remain valid.

To combine the economic and environmental objectives we can then combine the objective functions presented in (1) and (14):

$\operatorname{Min} \alpha \cdot Z_{1}+\beta \cdot Z_{2}$

subject to constraints $(2)-(13)$

The parameters $\alpha$ and $\beta$ used in this model are weights for the two objectives. It should be noted that these also need to reflect the units in which both of the objectives are expressed, to make sure both objectives are actually considered in the optimization. Some experimenting with the model might be necessary to determine a good range for these parameters. This combined model allows us to illustrate trade-offs between the economic and environmental objective. For various values of $\alpha$ and $\beta$ the model would provide different production and distribution scenarios, and would e.g. be able to illustrate how much efficiency one has to give up to obtain a certain decrease of the environmental impact.

\section{CONCLUSIONS AND FURTHER RESEARCH}

This paper presents a modelling approach for the sustainable production and distribution of professionally prepared meals. We first discuss the sustainability issues involved in the system, after which the relevant planning decisions are identified and organised in a decision hierarchy. A mathematical model to support decision making focused on tactical distribution network planning is proposed after that. The decisions 
supported include the production quantities and the enthalpy level of the produced product, but also the packaging type and the delivery structure used to distribute the products to the professional kitchens. Both economic and environmental aspects are considered in the evaluation of the production and distribution system, and the model can therefore be used to gain insight in the complex interactions between these aspects, and eventually lead to a sustainable production and distribution systems for high-quality meals in the catering industry.

In parallel research projects, performed by research partners, there will be more focus on the development of meal elements and the technological aspects of super chilling. Also, a sensory analysis of prepared meals will be performed. In our future research, these results will be combined with our current work to improve the decision support models on the different hierarchy levels. The models will then also be evaluated in a representative case study, which altogether acts as a feasibility study for the new production and distribution concept for professionally prepared meals.

\section{REFERENCES}

[1] Mikkelsen, B.E., A.M. Beck, A. Lassen, "Do recommendations for institutional food service result in better food service? A study of compliance in Danish hospitals and nursing homes from 1995 to 2002-2003", European Journal of Clinical Nutrition, Vol. 61, No. 1, pp. 129-134, 2007.

[2] Hartwell, H.J., J.S.A. Edwards, C. Symonds, "Foodservice in hospital: development of a theoretical model for patient experience and satisfaction using one hospital in the UK National Health Service as a case study", Journal of Foodservice, Vol. 17, No. 5-6, pp. 226-238, 2006.

[3] Wright, O.R.L., L.B. Connelly, S. Capra, "Consumer evaluation of hospital foodservice quality: an empirical investigation", International Journal of Health Care Quality Assurance, Vol. 19, No. 2, pp. 181-194, 2006.

[4] Buckley, M., C. Cowan, M. McCarthy, "The convenience food market in Great Britain: Convenience food lifestyle (CFL) segments", Appetite, Vol. 49, No. 3, pp. 600-617, 2007.

[5] Engelund, E.H., L.A. Schultz, J. Adler-Nissen, "Meal elements - new convenience products to increase foodservice meal quality", Working Paper, Technical University of Denmark, 2008.

[6] Duy Bao, H.N., S. Arason, K.A. Porarinsdottir, "Effects of dry ice and superchilling on quality and shelf life of arctic charr (Salvelinus alpinus) fillets", International Journal of Food Engineering, Vol. 3, No. 3, Article 7, 2007.

[7] Singh, R.P., D.R. Heldman, Introduction to Food Engineering, $4^{\text {th }}$ ed., Academic Press, NY, 2009.
[8] Mattson, B., U. Sonesson, Environmentally- friendly food production, Woodheart Publishing Limited, Cambridge, UK, 2003.

[9] Van der Vorst, J.G.A.J., S.O. Tromp, D.J. Van der Zee, "Simulation modelling for food supply chain redesign; integrated decision making on product quality, sustainability and logistics", to be published in International Journal of Production Research, (doi: 10.1080/00207540802356747), 2008.

[10] Kleindorfer, P.R., K. Singhal, L.N. Van Wassenhove, "Sustainable Operations Management", Production and Operations Management, Vol. 14, No. 4, pp. 482-492, 2005.

[11] Karagozoglu, N., M. Lindell, "Environmental management: Testing the win-win model", Journal of Environmental Planning and Management, Vol. 43, No. 6, pp. 817-829, 2000.

[12] Akkerman, R., D.P. van Donk, "Balancing environmental and economic performance in the food-processing industry", to be published in International Journal of Entrepreneurship and Innovation Management, 2009.

[13] Corbett, C.J., R.D. Klassen, "Extending the horizons: Environmental excellence as key to improving operations", Manufacturing \& Service Operations Management, Vol. 8, No. 1, pp. 5-22, 2006.

[14] Azapagic, A., A. Millington, A. Collett, "A methodology for integrating sustainability considerations into process design", Chemical Engineering Research and Design, Vol. 84, No. A6, pp. 439-452, 2006.

[15] Edwards, M.F., "Product engineering: Some challenges for chemical engineers", Chemical Engineering Research and Design, Vol. 84, No. A4, pp. 255-260, 2006.

[16] Hax, A.C., H.C. Meal, "Hierarchical integration of production planning and scheduling", in Geisler, M.A. (Ed.), Studies in Management Science, Vol. 1, Elsevier, New York, NY, 1975.

[17] Meal, H.C., "Putting production decisions where they belong", Harvard Business Review, Vol. 62, No. 2, pp. 102-111, 1984.

[18] Wang, Y, R. Akkerman, M. Grunow, "Challenges in supply chain management of professionally prepared meals", Proceedings of the 16th International EurOMA Conference, June 14-17, 2009, Göteborg, Sweden, 2009.

[19] Rong, A., R. Akkerman, M. Grunow, "Mixed-integer linear programming approach for food production and distribution planning", Pre-prints of the Fifteenth International Working Seminar on Production Economics, March 3-7, 2008, Innsbruck, Austria, Vol. 2, pp. 559-570, 2008.

[20] Hauschild, M., J. Jeswiet, L. Alting, "From life cycle assessment to sustainable production: Status and perspectives", CIRP Annals - Manufacturing Technology, Vol. 54, No. 2 , pp. 535-555, 2005. 